\title{
EFEITOS DA ALTURA DE COLHEITA DA SILAGEM DE MILHO E DO NÍVEL DE CONCENTRADO SOBRE AS CARACTERÍSTICAS DA CARCAÇA E DA CARNE DE NOVILHOS SUPERJOVENS
}

\author{
Fabiano Nunes Vaz, ${ }^{1}$ João Restle, ${ }^{2}$ Eduardo da Costa Eifert,${ }^{3}$ Ivan Luis Brondani, ${ }^{4}$ \\ Ricardo Zambarda Vaz ${ }^{5}$ Flânia Mônego Argenta ${ }^{6}$ \\ 1. Doutor, professor adjunto da Universidade Federal do Pampa. E-mail: fabianovaz@unipampa.edu.br. \\ 2. PhD, professor visitante da Universidade Federal de Goiás. E-mail: jorestle@terra.com.br. \\ 3. Doutor, pesquisador da Embrapa Arroz e Feijão. E-mail: eifert@cnpaf.embrapa.br \\ 4. Doutor, professor adjunto da Universidade Federal de Santa Maria. E-mail: brondani@ccr.ufsm.br \\ 5. Doutor, professor da Universidade Integrada da Região das Missões. E-mail: rzvaz@terra.com.br \\ 6. Mestranda do Programa de Pós-Graduação em Zootecnia, Universidade Federal de Santa Maria. E-mail: ppgz@mail.ufsm.br
}

\section{RESUMO}

Este trabalho foi desenvolvido com o objetivo de estudar os efeitos da elevação da altura de corte da silagem de milho de 16 para $46 \mathrm{~cm}$, associados aos níveis de $16 \%$ ou $30 \%$ de concentrado sobre o total da matéria seca oferecida, sobre as características da carcaça de bezerros. Utilizaram-se 24 bezerros Braford, desmamados aos três meses de idade e terminados em confinamento dos sete aos doze meses de idade, quando foram abatidos. Não se observou interação entre altura de corte e nível de concentrado. As variáveis percentagens dos cortes comerciais da carcaça, as medidas métricas da carcaça, bem como as percentagens de osso, de músculo e de gordura e relações entre os tecidos da carcaça não foram afetadas pela altura de colheita da silagem ou pelo nível de concentrado usado nas dietas. Alem disso, a carne de animais alimentados com nível mais baixo de concentrado teve menor perda durante o descongelamento $(5,05 \%$ vs $8,03 \%)$, resultando em maior suculência (7,14 vs 6,74 pontos), embora a carne apresentasse coloração mais escura que a carne dos outros novilhos (3,17 vs 4,00 pontos). Na comparação entre as alturas de colheita da silagem, a maior suculência foi observada na carne de animais alimentados com silagem colhida a $16 \mathrm{~cm}$ do solo $(7,18$ vs 6,69 pontos), cuja carne teve menor perda durante o descongelamento $(4,70$ vs $8,38 \%)$ e durante a cocção $(17,11$ vs $22,33 \%)$.

PALAVRAS-CHAVES: Braford, composição da carcaça, qualidade da carne, qualidade da silagem, volumoso.

\section{ABSTRACT}

\section{EFFECTS OF CORN SILAGE HARVEST HEIGHT AND CONCENTRATE LEVEL ON CARCASS AND MEAT CHARACTERISTICS OF BRAFORD YOUNG STEERS}

This work was conducted with the objective of verifying the effects of increasing the corn silage harvest height from 16 to $46 \mathrm{~cm}$, associated to 16 or $30 \%$ of concentrate level on total dry matter offered, on carcass and meat characteristics of young steers. Twenty-four Braford calves, weaned at three months of age, were finished in feedlot from seven to twelve months, when they were slaughtered. The commercial carcass cuts, metric carcass measurements, such as the bone, muscle and fat percentages and carcass tissues ratios were not affected by the silage harvest height and diet concentrate level used. On the other hand, meat of steers fed with low concentrate level had lower thawing loss (5.05 vs. 8.03\%) resulting in higher juiciness (7.14 vs. 6.74 points), although the meat showed darker coloration than the meat of the other steers (3.17 vs. 4.00 points). The comparison between harvest heights showed that meat of steers fed with silage harvested at $16 \mathrm{~cm}$ from the soil had higher juiciness (7.18 vs. 6.69 points), as the result showed lower thawing loss (4.70 vs. 8.38\%) and lower cooking loss (17.11 vs. $22.33 \%)$.

KEYWORDS: Braford, carcass composition, meat quality, roughage, silage quality. 


\section{INTRODUÇÃO}

Na bovinocultura de corte de ciclo completo, a redução de idade de abate dos machos representa um ponto importante ao incremento dos índices produtivos e eficiência do estabelecimento rural como empresa, no entanto somente é viável se os novilhos atingirem um grau de acabamento adequado às exigências do mercado.

Além de importantes para o sistema produtivo, o peso de abate e o acabamento são considerados os fatores principais que determinam a qualidade da carcaça e da carne (VAZ \& RESTLE, 1998). Por sua vez, redução da idade de abate beneficia a característica mais importante da carne bovina no que diz respeito à satisfação dos consumidores: a maciez (VAZ et al., 2002b; RESTLE \& VAZ, 2003; VAZ et al., 2004).

Dada a importância da redução da idade de abate nos índices produtivos e, consequentemente, econômicos da empresa rural (PACHECO et al., 2006), aliados à melhoria na qualidade da carne, várias pesquisas têm estudado a redução máxima da idade de abate dos novilhos. As pesquisas estão concentradas no estudo de animais abatidos com idade variando entre doze e quinze meses de idade, quando os animais têm condições de atingir peso de carcaça entre treze e quinze arrobas (RESTLE \& VAZ, 2003).

A redução da idade de abate passa pela melhoria na qualidade da alimentação dos animais. Assim, pode-se afirmar que as alterações na dieta afetam as características da carcaça e da carne, principalmente aquelas ligadas à deposição de tecidos na carcaça, sobretudo quanto à deposição de gordura, pois seus efeitos estão diretamente relacionados ao nível energético da alimentação oferecida aos animais (ARTHAUD et al., 1977).

Entretanto, o correto manejo da dieta está diretamente relacionada à lucratividade de um confinamento (CAÑAS et al., 1974; RESTLE et al., 2004). RESTLE et al. (2007), em avaliação econômica do confinamento de novilhos Red Angus superjovens, observaram que o custo da dieta é o item mais oneroso do processo, se desconsiderado o custo de aquisição dos animais. A fração volumosa, composta por silagem de milho, representou $18,9 \%$ do custo de engorda, com variação entre $18,7 \%$ e $19,2 \%$ em função do peso de abate dos animais (340 a $434 \mathrm{~kg}$ de peso vivo).
RESTLE et al. (2002a) verificaram que, no processo de colheita do milho para silagem, a elevação da altura de corte das plantas aumenta a participação de grãos em detrimento dos colmos e das folhas senescentes, melhorando a qualidade da silagem produzida, pela redução nos teores de fibra em detergente neutro e detergente ácido. Em seu trabalho, LEWIS et al. (2004) afirmam que as silagens de milho produzidas a partir dos diferentes híbridos disponíveis no mercado apresentam diferenças na digestibilidade da fibra detergente neutra, quando existe variação na altura de colheita entre 15 e $46 \mathrm{~cm}$ do solo, afetando o desenvolvimento dos animais, conforme também constatado por SPADOTTO et al. (1996). No entanto, WOODY et al. (1983) não observaram efeitos do incremento de grão na biomassa ensilada sobre as características organolépticas da carne.

ANDRADE et al. (1998) acreditam que essas variações podem ser afetadas pelas características do híbrido utilizado. Adicionalmente, são relativamente poucos os trabalhos que avaliam os efeitos de diferentes silagens usadas durante a engorda sobre as características da carcaça e da carne de novilhos.

O objetivo deste trabalho foi estudar os efeitos sobre as características de carcaça e da carne, de duas alturas de colheita da silagem de milho, associadas a dois níveis de concentrado na dieta oferecida a bezerros Braford, confinados dos sete aos doze meses de idade.

\section{MATERIAL E MÉTODOS}

O experimento foi realizado no Setor de Bovinocultura de Corte do Departamento de Zootecnia da Universidade Federal de Santa Maria (UFSM), no período compreendido entre maio e dezembro.

As carcaças avaliadas foram provenientes de 24 bezerros inteiros da raça Braford (3/8 Nelore 5/8 Hereford), desmamados precocemente aos 88 dias e mantidos em confinamento até os sete meses de idade. Ao início do experimento (sete meses), os bezerros apresentavam peso vivo médio de $221,2 \mathrm{~kg}$. A terminação em confinamento teve a duração de 158 dias, sendo então os animais abatidos aos doze meses de idade, quando atingiram peso vivo médio de 390,4 kg.

Os tratamentos corresponderam às dietas experimentais, as quais se constituíram de duas alturas de 
colheita da silagem de milho, denominadas corte baixo $(16 \mathrm{~cm})$ e corte alto $(46 \mathrm{~cm})$, associadas a dois níveis de concentrado, $16 \%$ e $30 \%$ em base seca, ou seja, relação volumoso/concentrado de $84 / 16$ e 70/30.

As dietas continham $12,7 \%$ de proteína bruta (isoproteicas), sendo a proporção dos ingredientes apresentada na Tabela 1 e a composição bromatológica das dietas apresentada na Tabela 2.

TABELA 1. Proporção dos ingredientes nas dietas experimentais, em base seca

\begin{tabular}{lrrrr}
\hline Ingredientes $(\%)$ & \multicolumn{2}{c}{ Corte baixo $(16 \mathrm{~cm})$} & \multicolumn{3}{c}{ Corte alto $(46 \mathrm{~cm})$} \\
\cline { 2 - 5 } & $16 \%$ conc. & $30 \%$ conc. & $16 \%$ conc. & $30 \%$ conc. \\
\hline Volumoso (sila- & 83,75 & 70,66 & 83,75 & 70,66 \\
gem de milho) & & & & \\
concentrado & & & & \\
Farelo de soja & 15,11 & 10,26 & 15,03 & 10,12 \\
Sorgo-grão & 0,00 & 17,54 & 0,00 & 17,69 \\
Mistura mineral ${ }^{1}$ & 1,12 & 1,01 & 1,12 & 1,08 \\
Ureia & 0,00 & 0,52 & 0,08 & 0,44 \\
Ionóforo & 0,02 & 0,01 & 0,02 & 0,01 \\
Total & 100,00 & 100,00 & 100,00 & 100,00 \\
\hline
\end{tabular}

${ }^{1}$ Composição: sal comum (80\%) mais calcário calcítico (20\%).

TABELA 2. Composição bromatológica das dietas experimentais

\begin{tabular}{lcccc}
\hline \multicolumn{1}{c}{$\begin{array}{l}\text { Variáveis (em \% } \\
\text { MS) }\end{array}$} & \multicolumn{2}{c}{ Corte baixo $(16 \mathrm{~cm})$} & \multicolumn{2}{c}{ Corte alto $(46 \mathrm{~cm})$} \\
\cline { 2 - 5 } Matéria seca & 42,30 & 48,79 & 43,09 & 49,51 \\
Matéria orgânica & 92,72 & 92,76 & 92,87 & 93,33 \\
Proteína bruta & 12,75 & 12,71 & 12,72 & 12,71 \\
Extrato etéreo & 2,82 & 2,87 & 3,07 & 3,09 \\
$\begin{array}{l}\text { Fibra em detergente } \\
\text { neutro }\end{array}$ & 43,58 & 38,44 & 37,67 & 33,49 \\
$\begin{array}{l}\text { Fibra em detergente } \\
\text { ácido }\end{array}$ & 26,47 & 23,21 & 20,97 & 18,60 \\
$\begin{array}{l}\text { Carboidratos totais } \\
\text { Carboidratos não }\end{array}$ & 77,14 & 77,21 & 77,08 & 77,54 \\
$\begin{array}{l}\text { fibrosos } \\
\text { Digestibilidade in } \\
\text { vitro da matéria } \\
\text { orgânica }\end{array}$ & 63,47 & 66,73 & 65,31 & 68,19 \\
\hline
\end{tabular}

Antes do embarque para o frigorífico, os animais foram pesados após jejum prévio de sólidos de quatorze horas. Após o abate, procedeu-se à identificação das carcaças, as quais foram lavadas, divididas em duas metades iguais, pesadas e levadas ao resfriamento por 24 horas à temperatura de $-2^{\circ} \mathrm{C}$. Decorrido esse tempo, retiraram-se as meia-carcaças da câmara fria, para realização das avaliações de maturidade fisiológica, conformação e medidas métricas de desenvolvimento da carcaça (MÜLLER, 1987).

Dividiu-se a meia-carcaça esquerda nos três cortes comerciais - dianteiro, costilhar ou ponta-de-agulha e traseiro ou serrote -, sendo pesados e expressos como porcentagem em relação ao peso da meia-carcaça.

Na meia-carcaça direita foram feitas as seguintes avaliações métricas: comprimento de perna, espessura de coxão e espessura de gordura subcutânea medida entre a $12^{\mathrm{a}}$ e $13^{\mathrm{a}}$ costelas. Nessa região, seccionouse transversalmente o músculo longissimus dorsi e, após exposição ao ar por vinte minutos, realizou-se avaliação subjetiva das características de cor, textura e marmoreio (MÜLLER, 1987).

Para determinação da composição física da carcaça em músculo, gordura e osso foi extraída uma peça correspondendo às $10^{\mathrm{a}}-11^{\mathrm{a}}-12^{\mathrm{a}}$ costelas, segundo a metodologia proposta por HANKINS \& HOWE (1946), adaptada por MÜLLER(1973), em que músculo = 15,56+0,81(MHH), gordura $=3,06+0,82(\mathrm{GHH})$, osso $=4,30+0,61(\mathrm{OHH})$. $\mathrm{MHH}, \mathrm{GHHe} \mathrm{OHH}$, respectivamente, músculo, gordura e osso, foram obtidos conforme metodologia de HANKINS \& HOWE (1946).

As porções de músculo longissimus dorsi extraídas dessa seção foram acondicionadas em sacos plásticos, embaladas em papel pardo e congeladas por trinta dias. Após esse período, com a amostra ainda congelada, cortaram-se dois bifes (A e B) com 2,5 cm de espessura de cada amostra. Um dos bifes (B) foi pesado ainda congelado. E depois de descongelados os bifes A e B, em refrigerador por um período de 24 horas, efetuou-se nova pesagem do bife $\mathrm{B}$, para determinação da perda durante o descongelamento.

Os dois bifes foram assados em forno, por quinze minutos, buscando uma temperatura de $70^{\circ} \mathrm{C}$ no interior das amostras. O bife A foi cortado ainda quente, em cubos de $2 \mathrm{~cm}^{3}$, e distribuídos aleatoriamente para um painel de cinco degustadores devidamente treinados, os quais avaliaram subjetivamente as características 
de maciez, palatabilidade e suculência de acordo com a metodologia descrita por MÜLLER (1987). O bife $\mathrm{B}$ foi novamente pesado depois de frio, para determinação da perda durante a cocção e, na sequência, foi utilizado para a determinação da força de cisalhamento, utilizando o aparelho Warner Bratzler Shear. Para tanto, retiraram-se três amostras de feixes de fibras musculares, com área de $1 \mathrm{~cm}^{2}$, cortadas perpendicularmente à direção das fibras, realizando-se em cada amostra duas leituras, totalizando seis leituras por bife.

O delineamento experimental foi inteiramente casualizado com arranjo fatorial 2 x 2 (duas alturas de corte da silagem de milho $\mathrm{x}$ dois níveis de concentrado) e seis repetições, conforme o modelo estatístico:

$$
\mathrm{Y}_{\mathrm{ijk}}=\mu+\alpha_{\mathrm{i}}+\beta_{\mathrm{j}}+(\alpha \beta)_{\mathrm{ijj}}+\varepsilon_{\mathrm{ijk}},
$$

sendo $Y_{\mathrm{ijk}}$ o valor observado na i-ésima altura de corte no j-ésimo nível de concentrado na k-ésima repetição; $\mu$ a média geral da variável; $\alpha_{i}$ o efeito da i-ésima altura de corte; $\beta_{\mathrm{j}}$ o efeito do j-ésimo nível de concentrado; $(\alpha \beta)_{\mathrm{ij}}$ o efeito da interação entre i-ésima altura de corte e j-ésimo nível de concentrado; $\varepsilon_{\mathrm{ijk}}$ o efeito aleatório associado a cada observação pressuposto $\operatorname{NID}\left(0 ; \sigma^{2}\right)$.

Submeteram-se os dados à análise de variância pelo procedimento de Modelos Lineares Gerais (PROC GLM), ajustando-se suas médias pelo método dos Quadrados Mínimos (LSMEANS) e comparando-as pelo teste $t$ de Student (PDIFF) ao nível de 5\% de probabilidade de erro. Para isso foi utilizado o programa estatístico SAS (1999).

\section{RESULTADOS E DISCUSSÃO}

Não houve interação significativa $(\mathrm{P}>0,05)$ entre altura de corte $\mathrm{x}$ nível de concentrado para as varáveis dependentes estudadas, conforme mostrado na Tabela 3.

Não houve diferença entre alturas de colheita ou entre níveis de concentrado, para as medidas métricas da carcaça $(\mathrm{P}>0,05)$. Diferenças entre essas medidas poderiam ser esperadas em função de prováveis diferenças no desenvolvimento dos animais durante a fase de engorda (BERG \& BUTTERFIELD, 1976; DI MARCO, 2003), ou seja, efeito direto da alimentação recebida em confinamento.

RESTLE et al. (2002a) verificaram que o híbrido de milho AG-5011, colhido a $42 \mathrm{~cm}$ de altura, produz silagem com menor teor de MS, maior teor de
PB e 13,8\% a mais de DIVMO em relação à silagem colhida a $20 \mathrm{~cm}$ do solo. Isso resulta em energia digestível 13,4\% mais alta, além de redução de 13,2\% no teor de FDN. Pesquisando plantas de sorgo AG2006, colhidas a 45 ou $14 \mathrm{~cm}$ do solo, RESTLE et al. (2002b) verificaram menores teores de FDN e FDA e maior concentração de energia digestível por kg de MS. Esses fatores não resultaram em diferença significativa no ganho de peso diário dos animais, mas o uso da silagem de sorgo colhida a $45 \mathrm{~cm}$ resultou em melhor conversão alimentar durante a terminação de bezerros Braford.

A Tabela 4 apresenta as médias para as variáveis percentagens dos cortes comerciais, medidas métricas da carcaça, composição física da carcaça e maturidade fisiológica das carcaças.

TABELA 3. Valor das probabilidades para altura de corte, níveis de concentrado, interação e coeficiente de variação para as variáveis estudadas

\begin{tabular}{|c|c|c|c|c|}
\hline \multirow[b]{2}{*}{ Variáveis } & \multicolumn{3}{|c|}{ Valor de probabilidade } & \multirow{2}{*}{$\begin{array}{c}\mathrm{CV}^{1}, \\
\%\end{array}$} \\
\hline & $\begin{array}{l}\text { Altura de } \\
\text { corte }\end{array}$ & $\begin{array}{c}\text { Nível de } \\
\text { concen- } \\
\text { trado }\end{array}$ & Interação & \\
\hline Percentagem de dianteiro & 0,3117 & 0,0840 & 0,6683 & 2,7 \\
\hline Percentagem de costilhar & 0,3415 & 0,4656 & 0,4472 & 6,3 \\
\hline Percentagem de serrote & 0,7248 & 0,1767 & 0,8809 & 1,9 \\
\hline Comprimento de perna & 0,7582 & 0,6447 & 1,000 & 4,0 \\
\hline Espessura de coxão & 0,7010 & 0,9562 & 0,6220 & 7,8 \\
\hline Percentagem de osso & 0,7591 & 0,6200 & 0,4508 & 7,3 \\
\hline Percentagem de músculo & 0,1528 & 0,8926 & 0,2934 & 4,8 \\
\hline Percentagem de gordura & 0,0599 & 0,6927 & 0,3309 & 12,5 \\
\hline Maturidade fisiológica & 0,1934 & 0,0741 & 0,7905 & 5,5 \\
\hline Relação músculo/osso & 0,3393 & 0,4162 & 0,2800 & 10,2 \\
\hline Relação músculo/gordura & 0,0904 & 0,3567 & 0,3213 & 16,6 \\
\hline Relação músc.+gord./osso & 0,3502 & 0,3337 & 0,3831 & 7,8 \\
\hline Textura & 0,5343 & 0,0723 & 1,0000 & 16,1 \\
\hline Coloração & 0,2377 & 0,0064 & 1,0000 & 18,7 \\
\hline Marmoreio & 0,8298 & 0,4340 & 0,3566 & 45,9 \\
\hline $\begin{array}{l}\text { Perda durante o desconge- } \\
\text { lamento }\end{array}$ & 0,0078 & 0,0265 & 0,1134 & 46,6 \\
\hline Perda durante a cocção & 0,0079 & 0,0580 & 0,5316 & 21,9 \\
\hline Suculência & 0,0115 & 0,0318 & 0,0623 & 6,2 \\
\hline Palatabilidade & 0,0767 & 0,4587 & 0,1580 & 6,7 \\
\hline Maciez & 0,2105 & 0,0828 & 0,1097 & 17,7 \\
\hline WB Shear & 0,1857 & 0,1649 & 0,2651 & 45,8 \\
\hline
\end{tabular}

${ }^{1} \mathrm{CV}=$ Coeficiente de variação. 
TABELA 4. Percentagem dos cortes comerciais, comprimento de perna e espessura de coxão de novilhos superjovens terminados em confinamento com diferentes alturas de corte da silagem de milho e níveis de concentrado na dieta

\begin{tabular}{|c|c|c|c|c|c|c|}
\hline \multirow[t]{2}{*}{ Variáveis } & \multicolumn{3}{|c|}{ Altura de corte } & \multicolumn{3}{|c|}{ Nível de concentrado } \\
\hline & $16 \mathrm{~cm}$ & $46 \mathrm{~cm}$ & $\mathrm{P}^{1}$ & $16 \%$ & $30 \%$ & $\mathrm{P}$ \\
\hline Percentagem de dianteiro & 38,98 & 38,53 & $>0,05$ & 38,37 & 39,15 & $>0,05$ \\
\hline Percentagem de costilhar & 12,13 & 12,44 & $>0,05$ & 12,40 & 12,16 & $>0,05$ \\
\hline Percentagem de serrote & 48,89 & 49,03 & $>0,05$ & 49,23 & 48,68 & $>0,05$ \\
\hline Comprimento de perna, $\mathrm{cm}$ & 64,92 & 64,58 & $>0,05$ & 64,50 & 65,00 & $>0,05$ \\
\hline Espessura de coxão, cm & 23,58 & 23,29 & $>0,05$ & 23,46 & 23,42 & $>0,05$ \\
\hline Percentagem de osso & 15,40 & 15,23 & $>0,05$ & 15,18 & 15,41 & $>0,05$ \\
\hline Percentagem de músculo & 65,84 & 63,96 & $>0,05$ & 64,81 & 64,99 & $>0,05$ \\
\hline Percentagem de gordura & 18,79 & 20,81 & $>0,05$ & 20,00 & 19,60 & $>0,05$ \\
\hline Relação músculo/osso & 4,23 & 4,31 & $>0,05$ & 4,29 & 4,25 & $>0,05$ \\
\hline Relação músculo/gordura & 3,15 & 3,55 & $>0,05$ & 3,30 & 3,39 & $>0,05$ \\
\hline Relação músc.+gord./osso & 5,60 & 5,54 & $>0,05$ & 5,61 & 5,52 & $>0,05$ \\
\hline Maturidade fisiológica, pontos ${ }^{1}$ & 14,08 & 13,67 & $>0,05$ & 13,58 & 14,17 & $>0,05$ \\
\hline
\end{tabular}

${ }^{1}$ Probabilidade pelo teste $\mathrm{t}$

${ }^{2}$ Variação de 1 a 15 pontos, sendo $1=$ maturidade mais avançada.

BRONDANI et al. (2004) testaram os níveis de concentrado $12 \%$ ou $32 \%$ na dieta de bezerros inteiros abatidos aos treze meses de idade, das raças Aberdeen Angus e Hereford, verificando maior comprimento de perna em animais alimentados com nível mais alto de energia. O nível de concentrado de $32 \%$ resultou em $71,75 \mathrm{~cm}$ de perna em comparação a $64,50 \mathrm{~cm}$ nos animais com nível baixo de energia, mas os autores não observaram diferenças para as variáveis comprimento de carcaça, espessura de coxão, comprimento e perímetro de braço.

Em análises de contraste para comparação do ganho médio diário antes e após o desmame, VAZ et al. (2004) verificaram que somente o ganho de peso antes dos sete meses de idade foi importante para características como peso aos doze e dezoito meses de idade, comprimento de carcaça e comprimento de perna. Esse efeito também influenciou a espessura de gordura subcutânea e, consequentemente, a percentagem de costilhar dos animais.

Outra forma de avaliar o desenvolvimento dos animais é pelos percentuais dos tecidos envolvidos no crescimento, principalmente o tecido adiposo (BERG \& BUTTERFIELD, 1976). Neste trabalho, a percentagem de gordura na carcaça apenas apresentou tendência $(\mathrm{P}<0,06)$ a ser maior nos animais alimentados com silagem cortada a $46 \mathrm{~cm}$, sugerindo maior concentração energética (Tabela 4). RIBEIRO et al. (2002) avaliaram níveis altos de concentrado na dieta, associados ao bagaço de cana, verificando que, entre $9 \%$ e $21 \%$ de bagaço de cana, não houve diferença no teor e na espessura de gordura da carcaça, apenas diferindo o peso de gordura pélvica + renal, que foi de 7,27 e $5,41 \mathrm{~kg}$, respectivamente, para os níveis $9 \%$ e $21 \%$ de bagaço de cana.

SIGNORETI et al. (1999), em abate de bezerros Holandês, confinados até o abate aos 190 ou 300 $\mathrm{kg}$ de peso vivo, com dietas contendo $45 \%, 60 \%$, $75 \%$ ou $90 \%$ de concentrado na base seca da ração, verificaram que a proporção de músculos diminuiu e que o percentual de gordura e as relações gordura/ osso e gordura/músculo aumentaram linearmente, em função do aumento dos níveis de concentrado, nos animais abatidos com $190 \mathrm{~kg}$. Nos animais abatidos com maior peso, o aumento do nível de concentrado nas rações influenciou somente a relação músculo/ osso na carcaça.

A conformação também foi similar entre todos os tratamentos (Tabela 4). Segundo DI MARCO (2003), a conformação é uma característica que pode 
ser afetada pela manipulação da dieta dos animais durante a fase de crescimento. Animais com crescimento restringido apresentam menor percentual de músculo na carcaça, prejudicando os escores de conformação. No presente trabalho, pode-se verificar que a percentagem de músculo da carcaça não diferiu entre os tratamentos $(\mathrm{P}>0,05)$, embora o teor de gordura tenha sido de $20,81 \%$ para os animais alimentados com silagem colhida a $46 \mathrm{~cm}$ do solo, ao passo que o corte mais baixo resultou em animais com $18,79 \%$ de gordura na carcaça. Entre os níveis de concentrado, os valores foram mais similares, 20,00 e 19,60, respectivamente, para os níveis $16 \%$ e $30 \%$ de concentrado na dieta $(\mathrm{P}>0,05)$.

VAZ \& RESTLE (2003) observaram que ganhos de peso médio diário superiores a $0,5 \mathrm{~kg}$, antes e após o desmame, resultam em novilhos Charolês com maior espessura de gordura que os animais com menor ganho de peso após os sete meses, independente se antes dos sete meses o ganho de peso foi superior ou inferior a $0,5 \mathrm{~kg}$. O percentual de gordura na carcaça mostrouse maior nos animais com ganhos baixo antes e alto após os sete meses $(17,3 \%)$ em relação aos animais com ganhos baixo, antes e após os sete meses de idade $(14,6 \%)$.

Pela Tabela 4, verifica-se que não houve diferença significativa entre os tratamentos para as percentagens dos cortes comerciais da carcaça. Utilizando os níveis de concentrado $12 \%$ ou $32 \%$ na dieta de bezerros de raças britânicas abatidos aos treze meses de idade, BRONDANI et al. (2004) não observaram diferenças nos percentuais de dianteiro, de costilhar e de serrote.

Em descrição do efeito do ganho de peso antes e após os sete meses de idade sobre as características de carcaça de novilhos Nelore abatidos aos 24 meses de idade, VAZ et al. (2004) verificaram maior percentagem de costilhar nos novilhos que tiveram altos ganhos de peso antes dos sete meses de idade $(13,8 \%)$ em relação aos novilhos com ganhos mais baixos do nascimento aos sete meses e ganho alto após os sete meses $(12,7 \%)$. Também os novilhos com ganho baixo antes e após os sete meses foram inferiores na percentagem de costilhar $(12,1 \%)$ em relação aos primeiros. Entretanto, os autores verificaram que a percentagem de serrote foi menor nestes $(48,4 \%) \mathrm{em}$ relação aos animais com ganhos de peso baixo antes e após os sete meses de idade (50,2\%). As análises de contraste desenvolvidas no trabalho de VAZ et al. (2004) indicaram que tanto o ganho de peso pré e após os sete meses de idade influenciam o peso de carcaça e a percentagem de serrote.

COSTA et al. (2002) verificaram, por meio de correlações, que as percentagens dos cortes comerciais da carcaça são características que, na mesma raça, podem ser afetadas pelo teor de gordura na carcaça. Para os autores, as deposições de gordura na carcaça favorecem o aumento do percentual de costilhar, o que seria o fator principal para que as percentagens dos cortes comerciais difiram entre animais de mesma raça, condição sexual e idade. COSTA et al. (2002) relataram correlação da espessura de gordura com o peso de costilhar de 0,65 $(\mathrm{P}=0,0005)$. Da primeira com a percentagem de costilhar, a correlação foi de $0,48(\mathrm{P}=0,0156)$.

Variando os níveis de energia para vacas de descarte suplementadas em pastagem cultivada, com níveis de concentrado entre de $0 \%$ a $0,9 \%$ do peso vivo, RESTLE et al. (2001) verificaram porcentagem de costilhar similar entre todos os tratamentos: entre $12,2 \%$ e $13,0 \%$. Entretanto, a espessura de gordura apresentou efeito linear positivo com o aumento do nível de concentrado na dieta, variando de 2,3 a $3,8 \mathrm{~mm}$.

Na Tabela 5 são mostradas as médias para as características relacionadas à qualidade da carne. Verificase que as médias foram similares entre alturas de corte ( $\mathrm{P}>0,05)$, para as características coloração, textura e marmoreio da carne. BRONDANI \& RESTLE (1991) observou que a textura da carne de animais alimentados com cana-de-açúcar apresentou-se mais grosseira que a dos alimentados com silagem de milho.

Contrastando novilhos Charolês com ganhos de peso alto ou baixo, antes e após os sete meses de idade, VAZ \& RESTLE (2003) verificaram maior marmoreio no grupo com ganhos de peso altos, antes e após os sete meses, em relação àqueles que ganharam menos de $0,5 \mathrm{~kg}$, dos sete aos 24 meses de idade. No mesmo grupo de animais a carne teve melhor coloração $(4,27$ pontos) que os animais com ganhos alto antes dos sete meses e baixo após os sete meses (3,22 pontos). Conforme VAZ \& RESTLE (2003), para as características da carne, o baixo ganho de peso antes dos sete meses pode ser compensado com ganhos maiores no 
período subsequente e vice-versa, observando-se maior prejuízo, no primeiro caso, para peso de carcaça dos animais e, no segundo caso, para grau de acabamento das carcaças e marmoreio da carne.

TABELA 5. Textura, cor, marmoreio, perdas ao descongelamento e à cocção e características sensoriais da carne de novilhos superjovens terminados em confinamento com diferentes alturas de corte da silagem de milho e níveis de concentrado na dieta

\begin{tabular}{|c|c|c|c|c|c|c|}
\hline \multirow[t]{2}{*}{ Variáveis } & \multicolumn{3}{|c|}{ Altura de corte } & \multicolumn{3}{|c|}{ Nível de concentrado } \\
\hline & $16 \mathrm{~cm}$ & $46 \mathrm{~cm}$ & $\mathrm{P}^{1}$ & $16 \%$ & $30 \%$ & $\mathrm{P}$ \\
\hline Textura, pontos ${ }^{2}$ & 4,08 & 3,92 & $>0,05$ & 4,25 & 3,75 & $>0,05$ \\
\hline Coloração, pontos ${ }^{2}$ & 3,42 & 3,75 & $>0,05$ & 3,17 & 4,00 & $<0,05$ \\
\hline Marmoreio, pontos ${ }^{3}$ & 6,00 & 6,25 & $>0,05$ & 6,58 & 5,67 & $>0,05$ \\
\hline Perda ao descongelamento, $\%$ & 4,70 & 8,38 & $<0,05$ & 5,05 & 8,03 & $<0,05$ \\
\hline Perda à cocção, \% & 17,11 & 22,33 & $<0,05$ & 17,95 & 21,50 & $>0,05$ \\
\hline Suculência, pontos ${ }^{4}$ & 7,18 & 6,69 & $<0,05$ & 7,14 & 6,74 & $<0,05$ \\
\hline Palatabilidade, pontos ${ }^{4}$ & 6,68 & 7,03 & $>0,05$ & 6,93 & 6,79 & $>0,05$ \\
\hline Maciez painel, pontos ${ }^{4}$ & 7,92 & 7,21 & $>0,05$ & 8,06 & 7,06 & $>0,05$ \\
\hline Maciez, WB Shear, kgf & 4,06 & 5,25 & $>0,05$ & 4,03 & 5,28 & $>0,05$ \\
\hline
\end{tabular}

Em bezerros desmamados aos 119 dias de idade, não se verificou efeito dos níveis de energia durante o crescimento sobre o marmoreio (SCHOONMAKER et al., 2004), embora o teor de gordura no longissimus analisada em laboratório tenha diferido entre os níveis de energia da dieta pesquisados $(50 \%, 70 \%$ de grão ad libitum e dietas com $60 \%$ de silagem ad libitum). A relação entre marmoreio e maciez foi explicada por NISHIMURA et al. (1999) como resultado do crescimento exagerado de células adiposas no interior do músculo, causando desestruturação e enfraquecimento do tecido conectivo.

TATUM et al. (1982) verificaram que o marmoreio tem efeito baixo, mas positivo sobre todas as características relacionadas ao paladar da carne. Os autores relatam que a relação entre gordura subcutânea e as características organolépticas da carne não foi linear ou aditiva, mas acabamentos entre 7,6 e 10,2 mm podem ser indicativos de carnes com boa palatabilidade. Entretanto, comparada com o marmoreio, a cobertura de gordura tem pouca relação com a palatabilidade da carne. No entanto, o marmoreio associado com $7,6 \mathrm{~mm}$ de gordura facilita a predição da palatabilidade da carne, o que, segundo os autores, se torna mais difícil de estimar a partir do marmoreio, analisado de forma isolada.

Na Tabela 5 verifica-se que a coloração da carne foi similar entre as duas alturas de colheita da silagem estudadas $(\mathrm{P}>0,05)$, mas o nível de concentrado influenciou a coloração da carne $(\mathrm{P}<0,05)$, sendo a melhor coloração observada para o nível 30\%. Em uma revisão sobre coloração da carne, SEIDEMAN et al. (1982) não apontam o efeito da dieta como um dos fatores principais que afetam a coloração da carne bovina, todavia os autores salientam que a coloração da carne bovina é o fator mais importante na determinação de compra dos consumidores. LANARI et al. (2002) citam divergências sobre efeito das dietas e níveis de concentrado sobre a coloração da carne, mas, em seu trabalho, os autores não verificaram diferença na carne de animais alimentados com concentrado em relação aos mantidos em pastejo sem suplementação de grãos.

RIBEIRO et al. (2002) não verificaram diferença na coloração da carne de tourinhos jovens $3 / 4$ Europeu $1 / 4$ Zebu, variando as dietas entre $9 \%, 15 \%$ e $21 \%$ de 
bagaço de cana-de-açúcar in natura na matéria seca da dieta dos animais. VAZ et al. (2002a) suplementaram, em pastagem cultivada de estação fria, vacas de descarte Charolês, com quatro níveis de suplementação energética, variando de $0,0 \%$ a $0,9 \%$ do peso vivo, e não observaram efeito do nível de suplementação sobre as características cor, textura e marmoreio da carne. Estudando dois tipos de volumosos em confinamento (canade-açúcar ou silagem de milho), VAZ \& RESTLE (2005) observaram exatamente a mesma coloração (média de 4,67 pontos) na carne de novilhos Hereford.

A palatabilidade não sofreu efeito $(\mathrm{P}>0,05)$ do nível de concentrado ou da altura de corte da silagem (Tabela 5). Entretanto a carne de animais alimentados com silagem colhida a $16 \mathrm{~cm}$ foi significativamente $(\mathrm{P}<0,05)$ mais suculenta do que a carne dos animais alimentados com silagem cortada aos $46 \mathrm{~cm}$ do solo. Da mesma forma, o nível de concentrado mais baixo representou carne mais suculenta que o nível $30 \%$ de concentrado $(\mathrm{P}<0,05)$, resultado direto das menores perdas durante o descongelamento e a cocção da carne observadas nos tratamentos corte baixo e $16 \%$ de concentrado em relação aos outros.

KOOHMARAIE (2003) afirma que, em animais de mesma idade, o manejo da qualidade da dieta visando aumentar o marmoreio da carne seria a opção mais eficiente de melhorar a maciez da carne de animais confinados. No entanto, a maciez da carne avaliada pelo painel de degustadores está mais relacionada a fatores relacionados à idade, ao grupo genético, às variações individuais e aos manejos pré e pós-abate, do que propriamente à dieta (LAWRENCE \& FOWLER, 1997). Estudando níveis de concentrado, VAZ et al. (2005) constataram similaridade na suculência e na palatabilidade da carne dos novilhos, mas a maciez da carne avaliada pelo painel melhorou, à medida que aumentou o nível de concentrado, com 5,40; 5,71 e 6,42 pontos, respectivamente, para $25 \%, 35 \%$ e $45 \%$ de concentrado na base seca da dieta.

HEDRICK et al. (1983) concluíram que períodos curtos de confinamento podem melhorar as características sensoriais da carne e que períodos maiores aumentam o acabamento dos animais, porém não afetam as características sensoriais. Para o paladar norte-americano, animais terminados em pastagem apresentam carne com menos sabor do que animais alimentados com silagem de milho (HEDRICK et al., 1983).
NELSON et al. (2004), em pesquisa de níveis de gordura na dieta de novilhos confinados, notaram que não houve efeito sobre a palatabilidade, estabilidade da cor e retenção de água pela carne. VAZ et al. (2005) observaram que os animais alimentados com silagem de sorgo forrageiro apresentaram carnes com menor perda durante a cocção ( $26,7 \%$ contra $29,2 \%)$, de pior coloração (3,49 contra 4,00 pontos) e de melhor palatabilidade (6,37 contra 5,74 pontos) que os novilhos alimentados com silagem de sorgo duplo propósito.

Com relação à suculência, LAWRIE (2005) relata dois tipos de suculência percebida: a primeira é uma impressão de umidade durante os primeiros movimentos mastigatórios e a segunda é uma suculência sustentada principalmente pela salivação, que é estimulada pela gordura presente na carne. Para o autor, a suculência percebida nos movimentos mastigatórios ocorre nas amostras de carne de animais jovens e a segunda em animais com grande teor de marmoreio na carne. VAZ et al. (2007) observaram alta correlação $(r=0,78)$ entre a gordura de marmoreio e a suculência da carne de animais terminados em pastagem, o que se deve ao fato de o marmoreio permitir uma maior manutenção de líquidos retidos no músculo, diminuindo a perda de água durante a cocção (LAWRIE, 2005).

A capacidade de retenção de água da carne está diretamente ligada ao teor de marmoreio e à velocidade de queda do $\mathrm{pH}$ durante a glicólise post-mortem (LAWRIE, 2005). Quando as diferenças no marmoreio são leves, acredita-se que a variação seja determinada pelo $\mathrm{pH}, \mathrm{o}$ qual pode oscilar em função da dieta que os animais consumiam (VAZ \& RESTLE, 1998; LAWRIE, 2005).

Assim como similaridade na maciez da carne, a altura de colheita e os níveis de concentrado usados na dieta não afetaram $(\mathrm{P}>0,05)$ a força de cizalhamento das fibras da carne (Tabela 5). SCHOONMAKER et al. (2004) verificaram que a alimentação dos bezerros do desmame aos 260 dias de idade com dieta ad libitum, contendo $50 \%$ de grão, altera a maturidade fisiológica da carcaça e o marmoreio, bem como aumenta a força necessária para realizar o cizalhamento das fibras, se comparados a bezerros com alimentação baseada em feno. Em vacas de descarte suplementadas com $0 \%$, $0,3 \%, 0,6 \%$ ou $0,9 \%$ do peso vivo, não se observou efeito do nível de suplementação sobre as características sensoriais da carne e quebras ao descongelamento e à cocção das amostras de carne (VAZ et al., 2002a). 


\section{CONCLUSÕES}

A suculência da carne é melhor no corte a 46 $\mathrm{cm}$, resultado das menores perdas durante o descongelamento e a cocção. O nível $30 \%$ de concentrado produz carne de melhor coloração e menos suculência, resultado de maior perda de líquidos durante o descongelamento da carne.

\section{REFERÊNCIAS}

ANDRADE, J.B.; HENRIQUE, W.; BRAUN, G.; ROSANA, E. Produção de silagem e reciclagem de nutrientes em sete cultivares de milho. 1 Composição bromatológica. In: REUNIÃO ANUAL DA SOCIEDADE BRASILEIRA DE ZOOTECNIA, 35., 1998, Botucatu, SP. Anais... Botucatu: UNESP, v. 35, 1998. CD-ROM.

ARTHAUD, V. H.; MANDIGO, R. W.; KOCH, R. M.; KOTULA, A. W. Carcass composition, quality and palatability attributes of bulls and steers fed different energy levels and killed at four ages. Journal of Animal Science, v. 44, n. 1, p. 56-64, 1977.

BERG, R. T.; BUTTERFIELD, R. M. New concepts of cattle growth. Sydney: Sydney University Press, 1976. 239 p.

BERGEN, R.; MILLER, S. P.; WILTON J. W.; CREWS JUNIOR, D. H.; MANDELL, I. B. Genetic correlations between live yearling bull and steer carcass traits adjusted to different slaughter end points. 2. Carcass fat partitioning. Journal of Animal Science, v. 84, n. 2, p. 558-566, 2006.

BRONDANI, I. L.; RESTLE, J. Efeito de dietas contendo canade-açúcar ou silagem de milho no desempenho de novislho em confinamento. Ciência Rural, Santa Maria, RS, v. 21, n.1, p. 129-134, 1991.

BRONDANI, I. L.; SAMPAIO, A. A. M.; RESTLE, J.; BERNARDES, R. A. L. C.; PACHECO, P. S.; FREITAS, A. K.; KUSS, F.; PEIXOTO, L. A. O. Aspectos quantitativos de carcaças de bovinos de diferentes raças, alimentados com diferentes níveis de energia. Revista Brasileira de Zootecnia, v. 33, n. 4, p. 978-988, 2004.

CAÑAS, C. R.; GASTÓ, C. J. Costo de cosecha y eficiencia de producción em ecosistemas ganaderos. Ciencia e Investigación Agrária, v. 1, p. 179-185, 1974.

COSTA, E. C.; RESTLE, J.; VAZ, F. N.; ALVES FILHO, D. C.; BERNARDES, R. A. L. C.; KUSS, F. Características da carcaça de novilhos Red Angus superprecoces abatidos com diferentes pesos. Revista Brasileira de Zootecnia, v. 31, n. 1, p. 119-128, 2002.

DI MARCO, O. N. Crecimiento y respuesta animal. Balcarce: Associación Argentina de Producción Animal, 1994. 129 p.
HANKINS, O. G.; HOWE, P. E. Estimation of the composition of beef carcass and cuts. Washington, D. C.: United States Department of Agriculture, 1946. 20 p. (USDA, Technical Bulletin, 926).

HEDRICK, H. B.; PATERSON, J. A.; MATCHES, A. G.; THOMAS, J. D.; MORROW, R. E.; STRINGER, W. G.; LIPSEY, R. J. Carcass and palatability characteristics of beef produced on pasture, corn silage and corn grain. Journal of Animal Science, v. 57, n. 2 , p. $791-801,1983$.

KOOHMARAIE, M. Understanding and managing variation in meat tenderness. In: REUNIÃO ANUAL DA SOCIEDADE BRASILEIRA DE ZOOTECNIA, 40., 2003, Santa Maria. Anais... Santa Maria: Sociedade Brasileira de Zootecnia/V2 Comunicação, [2003]. CD-ROM. Palestras. Bovinocultura de Corte.

LANARI, M. C.; BREWSTER, M.; YANG, A.; TUME, R. K. Pasture and grain finishing affect the color stability of beef. Journal of Food Science, v. 67, n. 7, p. 2467-2473, 2002.

LAWRENCE, T. L. J.; FOWLER, V. R. Growth of farm animals. London: British Library, 1997. 330 p.

LAWRIE, R. A. Ciência da carne. 6. ed. Porto Alegre: Artmed, 2005. 384 p.

LEWIS, A. L.; COX, W. J.; CHERNEY, J. H. Hybrid, maturity, and cutting height interactions on corn forage yield and quality. Agronomy Journal, v. 96, p. 267-274, 2004.

MÜLLER, L. Normas para avaliação de carcaças e concurso de carcaças de novilhos. 2. ed. Santa Maria: Universidade Federal de Santa Maria, 1987. 31 p. (Departamento de Zootecnia, Boletim Técnico, 1).

NELSON, M. L.; MARKS, D. J.; BUSBOOM, J. R.; CRONRATH J. D.; FALEN, L. Effects of supplemental fat on growth performance and quality of beef from steers fed barley-potato product finishing diets: I. Feedlot performance, carcass traits, appearance, water binding, retail storage, and palatability attributes. Journal of Animal Science, v. 82, n. 11, p. 3600-3610, 2004.

NISHIMURA, T.; HATTORI, A.; TAKAHASHI, K. Structural changes in intramuscular connective tissue during the fattening of Japanese Black cattle: effect of marbling on beef tenderization. Journal of Animal Science, v. 77, n. 1, p. 93-104, 1999.

PACHECO, P. S.; RESTLE, J.; VAZ, F. N.; FREITAS, A. K.; PADUA, J. T.; NEUMANN, M.; ARBOITTE, M. Z. Avaliação econômica da terminação em confinamento de novilhos jovens e superjovens de diferentes grupos genéticos. Revista Brasileira de Zootecnia, v. 35, n. 1, p. 309-320, 2006.

RESTLE, J.; NEUMANN, M.; BRONDANI, I. L.; PASCOAL, L. L.; SILVA, J. H. S.; PELLEGRINI, L. G.; SOUZA, A. N. M. Ma- 
nipulação da altura de corte da planta de milho (Zea mays, L.) para ensilagem visando a produção do novilho superprecoce. Revista Brasileira de Zootecnia, v. 31, n. 3, p. 1235-1244, 2002a.

RESTLE, J.; NEUMANN, M.; BRONDANI, I. L.; ALVES FILHO, D. C.; BERNARDES, R. A. L. C.; ARBOITTE, M. Z.; ROSA, J. R. P. Manipulação do corte do sorgo (Sorghum bicolor, L. Moench.) para confecção de silagem, visando a produção do novilho superprecoce. Revista Brasileira de Zootecnia, v. 31, n. 3, p. 1481-1490 (Suplemento), 2002 b.

RESTLE, J.; PACHECO, P. S.; COSTA, E. C. da; FREITAS, A. K.; VAZ, F. N.; BRONDANI, I. L.; FERNANDES, J. J. R. Apreciação econômica da terminação em confinamento de novilhos Red Angus superjovens abatidos com diferentes pesos. Revista Brasileira de Zootecnia, v. 36, n. 4, p. 978-986, 2007.

RESTLE, J.; PACHECO, P. S.; VAZ, F. N. Produção de carne bovina na Região Sul: tecnologias e informações para o desenvolvimento sustentável. In: SIMPÓSIO DE PRODUÇÃODE GADO DE CORTE, 4., 2004, Viçosa, MG. Anais... Viçosa: UFV, v. 4, p. 185-221, 2004. 484 p. <http:// www.simcorte.com/index/Palestras/q_ simcorte/simcorte5.PDF>

RESTLE, J.; VAZ, F. N. Eficiência e qualidade na produção de carne bovina. In: REUNIÃO ANUAL DA SOCIEDADE BRASILEIRA DE ZOOTECNIA, 40., 2003, Santa Maria. Anais... Santa Maria: Sociedade Brasileira de Zootecnia/V2 Comunicação, [2003]. CDROM. Palestras. Bovinocultura de Corte.2003 SBZ Sta. Maria. $<$ http://www.sbz.org.br/cds/SBZ2003.rar $>$

RESTLE, J.; VAZ, F. N.; ALVES FILHO, D. C.; PASCOAL, L. L.; OLIVEIRA, A. N.; FATURI, C.; ARBOITTE, M. Z. Efeito da suplementação energética sobre a carcaça de vacas de diferentes idades, terminadas em pastagem cultivada de estação fria sob pastejo horário. Revista Brasileira de Zootecnia, v. 30, n. 3, p. 1076-1083, 2001 (Suplemento 1).

RIBEIRO, F. G.; LEME, P. R.; BULLE, M. L. M.; LIMA, C. G.; LUZ E SILVA, S.; PEREIRA, A. S. C.; LANNA, D. P. D. Características da carcaça e qualidade da carne de tourinhos alimentados com dietas de alta energia. Revista Brasileira de Zootecnia, v. 31, n. 2, p. 749-756, 2002.

SAS - Statistical Analysis System. SAS System for Windows. Cary: SAS Institute Inc., v. 8.0, 1999.

SCHOONMAKER, J. P.; CECAVA, M. J.; FLUHARTY, F. L.; ZERBY, H. N.; LOERCH, S. C. Effect of source and amount of energy and rate of growth in the growing phase on performance and carcass characteristics of early- and normal-weaned steers. Journal of Animal Science, v. 82, n. 1, p. 273-282, 2004.

SEIDEMAN, S. C.; CROSS, H. R.; SMITH, G. C.; DURLAND, P. R. Factors associated with fresh meat color: a review. Journal of Food Quality, v. 6, n. 3, p. 211-237, 1984.
SIGNORETTI, R. D.; ARAUJO, G. G. L.; SILVA, J. F. C. Composição física da carcaça de bezerros da raça Holandesa alimentados com dietas contendo diferentes níveis de concentrado. Revista Brasileira de Zootecnia, v. 28, n. 1, p. 883-888, 1999.

SPADOTTO, A. J.; SILVEIRA, A. C.; FURLAN, L. R. ARRIGONI, M. B.; COSTA, C.; OLIVEIRA, H. N.; PARRÉ, C. Avaliação da silagem de milho das variedades graníferas e forrageira no desempenho de bovinos das raças Nelore e Canchim em regime de confinamento. Revista da Sociedade Brasileira de Zootecnia, v. 26, n. 1, p. 1-12, 1996.

TATUM, J. D.; SMITH, G. C.; CARPENTER, Z. L. Interrelationships between marbling, subcutaneous fat thickness and cooked beef palatability. Journal of Animal Science, v. 54, n. 3 , p. $777-784,1982$.

VAZ, F. N.; RESTLE, J. Características de carcaça e da carne de novilhos Hereford terminados em confinamento com diferentes fontes de volumoso. Revista Brasileira de Zootecnia, v. 34, n. 1, p. 230-238, 2005.

VAZ, F. N.; RESTLE, J. Ganho de peso antes e após os sete meses no desenvolvimento e nas características de carcaça e carne de novilhos Charolês abatidos aos dois anos Revista Brasileira de Zootecnia, v. 32, n. 3, p. 699-708, 2003.

VAZ, F. N.; RESTLE, J. Produção de carne com qualidade. In: RESTLE, J.; BRONDANI, I. L.; PASCOAL, L. L. et al. (Ed.). Produção intensiva com qualidade em bovinos de corte. Santa Maria: UFSM, 1998. p. 104-119.

VAZ, F. N.; RESTLE, J.; BRONDANI, I. L.; COSTA, E. C.; VAZ, R. Z.; ROSO, C.; CARRILHO, C. O. Suplementação energética sobre a qualidade da carcaça e da carne de vacas de diferentes idades, terminadas em pastagem cultivada de estação fria sob pastejo horário. Revista Brasileira de Zootecnia, v. 31, n. 1, p. 173-182, 2002a.

VAZ, F. N.; RESTLE, J.; VAZ, R. Z.; BRONDANI, I. L.; BERNARDES, R. A. L. C.; FATURI, C. Efeitos de raça e heterose na composição física da carcaça e na qualidade da carne de novilhos da primeira geração de cruzamento entre Charolês e Nelore. Revista Brasileira de Zootecnia, v. 31, n. 1, p. 376-386, 2002 b. (Suplemento).

VAZ, F. N.; RESTLE, J.; PADUA, J. T.; METZ, P. A. M.; MOLETTA, J. L.; FERNANDES, J. J. R. Qualidade da carcaça e da carne de novilhos abatidos com pesos similares, terminados em diferentes sistemas de alimentação. Ciência Animal Brasileira, v. 8 , n. 1 , p. $31-40,2007$.

VAZ, F. N.; RESTLE, J. SILVA, N. L. Q.; ALVES FILHO, D. C.; PASCOAL, L. L.; BRONDANI, I. L.; KUSS, F. Nível de concentrado, variedade da silagem de sorgo e grupo genético sobre a 
qualidade da carcaça e da carne de novilhos confinados. Revista Brasileira de Zootecnia, v. 34, n. 1, p. 239-249, 2005.

VAZ, F. N.; RESTLE, J.; VAZ, R. Z.; BRONDANI, I. L.; PÁDUA, J. T.; PACHECO, P. S.; SANTOS, A. P. Ganho de peso antes e após os sete meses no desenvolvimento e características quantitativas da carcaça de novilhos Nelore abatidos aos dois anos. Revista Brasileira de Zootecnia, v. 33, n. 4, p. 1029-1038, 2004.

WOODY, H. D.; FOX, D. G.; BLACK, J. R. Effect of grain content on performance of growing and finishing cattle. Journal of Animal Science, v. 57, p. 717-728, 1977.

Protocolado em: 26 jul. 2007. Aceito em: 11 mar. 2010. 